\title{
Predatory Activity of the Fungus Pleurotus eryngii on Ancylostoma caninum Infective Larvae
}

\author{
Aline del Carmen Garcia Lopes ${ }^{1}$, Emy Hiura ${ }^{1}$, Filippe Elias de Freitas Soares ${ }^{1}$, Leandro Abreu da \\ Fonseca $^{2}$, Caio Colodette Sena ${ }^{1}$, Carolina Magri Ferraz ${ }^{1}$, Tracy Lacerda ${ }^{1}$, Thiago Senna ${ }^{1}$, Anderson \\ Rocha Aguiar ${ }^{1}$, Andreia Luiza Araújo ${ }^{1}$, Jackson Victor de Araújo ${ }^{2}$, Fabio Ribeiro Braga ${ }^{1 *}$ \\ ${ }^{1}$ Department of Parasitology, University of Vila Velha-ES, Vila Velha-ES, CEP: 29102206, Brazil \\ ${ }^{2}$ Department of Veterinary Medicine, Federal University ofViçosa, Viçosa-MG. Cep: 3657000, Brazil
}

Received: April 06, 2015; Accepted: May 20, 2015; Published: June 27, 2015

*Corresponding author: Fabio Ribeiro Braga, Department of Parasitology, University of Vila Velha-ES, CEP: 29102206, Brazil, Fax: +55 (31) $3899-$ 1464; E-mail: fabioribeirobraga@hotmail.com

\begin{abstract}
The objective of this study was to evaluate in vitro predatory activity of Pleurotus eryngii fungal isolates on A. caninum of dogs. In the treated group, $1000 \mathrm{~A}$. caninum larvae and 50 microliters of the fungal isolatewere placed in each petri dish, and in the control group only 1000 larvae were placed. The $P$. eryngii fungal isolatereduced the average number of $A$. caninum larvae compared to control ( $p<$ 0.01 ) and presented a reduction percentage of $47.56 \%$. The average number of $\mathrm{L} 3$ recovered in the treated group was $32.2( \pm 15.3)$ while the average in the control group was $72.88( \pm 27.0)$. Consecutive reduction was observed from day 1 to day 7 in relation to the number of larvae in both groups $(p<0.01)$. It is concluded that the fungus $P$. eryngii showed predatory activity on A. caninum L3, and may be a control alternative.
\end{abstract} fungi

Keywords: Ancylostomids; Biological control; Nematophagous

\section{Introduction}

Dogs, despite the benefits which present as pets, may be considered as reservoirs of infectious agents such as parasites, bacteria, viruses and fungi and may be a potential source of contamination and risk to human health. Due to its zoonotic potential, among the gastrointestinal helminths, Ancylostoma spp has attracted great attention. Ancylostoma caninum and $A$. braziliense are intestinal geohelminths from dogs and cats and have required great attention because of their zoonotic potential by means of direct soil contamination with the faeces of infected animals, since their infective larvae (L3) are present in this contaminated environment [1,2]. Nowadays alternative measures to control these and other domestic animal endoparasitosis are searched in order to decrease use of chemotherapeutics and, consequently, the reduction of pollutant levels in the environment and in animal originating products [3]. In order to improve this control, use of biological control is suggested as a viable and promising alternative that reduces infections caused by gastrointestinal helminth parasites present in the environment, and whose action takes place by means of living organisms that act as natural antagonists in the environment $[1,4]$. Among these antagonists are the nematophagous fungi. These fungi have predatory capacity on helminths and constitute an option for the control of free-living stages of helminths of dogs and cats $[1,4]$. Nematophagous fungi include those fungi which attack larvae and/or eggs from these animals and use them as a nutrient source $[3,5]$.

The species of nematophagous fungi prey the L3 of gastrointestinal nematodes and have been studied for their potential as biological control agents of gastrointestinal nematodes from domestic animals [6,7]. In this sense, the Pleurotus genre produces Nematotoxin, a toxin capable of immobilizing the nematodes that come in contact with it [8]. This fungus may be found in decaying wood and also commercially cultivated in several countries for human consumption. Regarding the general mechanism of "attack" of fungi on L3 or even to helminth eggs, literature mentions that nematophagous fungi attack by various processes, including: (a) capture; (b) parasitism and (c) production of toxins and enzymes [9]. In relation to the extracellular enzymes, including serine proteases (EC 3.4.21), chitinases (EC 3.2.1.14) and collagenases (EC 3.4.24.3), these are important virulence factors that can degrade the main chemical constituents of the nematodes' cuticle and eggshell. According to Kwok et al. [10] aerial hyphae of Pleurotus spp. have produced small droplets of toxin on agar culture, which were identified as trans-2-decenedioic acid. Overall, the nematodes that come in contact with this toxin are paralyzed and subsequently invaded by hyphae. This attack mechanism on the nematodes was observed in several species of Pleurotus spp, such as Pleurotus dryinus, P. euosmus, and P. eryngii, among others. In another context, literature shows research regarding in vitro biological control of $A$. caninum L3. However, this is the first report of predatory activity of $P$. eryngii on this nematode.

Thus, the present study aimed to evaluate the efficiency of the fungus Pleorotus eryngii on in vitro control of Ancylostoma caninum L3. 


\section{Materials and methods Obtaining of the fungal isolate}

Nematophagous fungus $P$. eryngii was used. This isolate is derived from the Parasitology Laboratory of the Federal University of Viçosa, Minas Gerais, and Brazil. This isolate has been maintained by continuous transfer to culture medium containing $2 \%$ water-agar.

\section{Obtaining conidia}

Culture dishes with $4 \mathrm{~mm}$ diameter were extracted from the fungal isolates maintained in test tubes containing $2 \%$ cornmeal-agar (2\% CMA) and transferred to Petri dishes of $9.0 \mathrm{~cm}$ in diameter containing $20 \mathrm{ml}$ of $2 \%$ potato dextrose agar, kept at $25^{\circ} \mathrm{C}$ in the dark for 10 days. After the growth of the isolates, new $4 \mathrm{~mm}$ diameter culture dishes were transferred to Petri dishes of $9.0 \mathrm{~cm}$ in diameter containing $20 \mathrm{ml}$ of $2 \%$ water-agar ( $2 \% \mathrm{WA}$ ) in which were added $1 \mathrm{ml}$ of distilled water containing 1,000 Panagrellus spp. larvae, a free-living nematode, daily over a period of 21 days to induce formation of fungal conidia. When complete fungal growth was observed, $5 \mathrm{ml}$ of distilled water was added to each Petri dish, and the conidia and mycelial fragments were removed using technique described by Araujo et al. [11].

\section{Obtaining Ancylostoma caninum larvae}

Fresh faeces were obtained from dogs living in the state of Espírito Santo. From these fecal samples about 3-5g of feces were taken for performance of the Willis-Mollay technique (fluctuation) in order to identify eggs present in the samples. After identification of Ancylostoma caninum eggs, fecal cultures were prepared with about $20 \mathrm{~g}$ of feces and they were incubated in a BOD incubation chamber fora period of 7 days. After this period the larvae were extracted and identified by the Baermann technique.

\section{Experimental assay}

An in vitro experimental assay was carried out. In the experiment the nematicidal activity of the fungus $P$. eryngii on $A$. caninum L3 and control group (no fungus) was evaluated. Thirty Petri dishes of $9.0 \mathrm{~cm}$ in diameter were prepared containing 20 $\mathrm{ml}$ of $1 \% \mathrm{WA}$, fifteen plates from the treated group and fifteen plates from the control group. In the treated group, in each Petri plate $30 \mu \mathrm{l}$ of the solution containing the L3 (1000 A. caninum larvae) and $50 \mu \mathrm{l}$ of fungal isolate (1000 conidia) were added. In the control group (without fungi) only the L3 were placed on the plates. For seven days, every 24 hours, 10 random fields of $4 \mathrm{~mm}$ in diameter in each plate from the treated and control groups were observed under a light microscope at 10x objective, and the number of larvae was counted in each of the fields. At the end of seven days, the non-predated larvae were recovered from the content of the petri dishes using the Baermann apparatus with water at $42^{\circ} \mathrm{C}[12]$.

\section{Statistical analysis}

The average of $A$. caninum L3 recovered was calculated. Data was interpreted by analysis of variance at significance levels of 1 and $5 \%$ of probability. The efficiency of larvae predation in relation to control was evaluated by the Tukey test at $1 \%$ probability. Subsequently, the average reduction percentage of L3 was calculated according to the following formula:

$$
\% \text { Reduction }=\frac{\left(\begin{array}{l}
\text { Average of recovered } \mathrm{L}_{3} \text { from control }- \\
\text { Average of recovered } \mathrm{L}_{3} \text { from treatment }
\end{array}\right)}{\text { Average of recovered } \mathrm{L}_{3} \text { from control }} \times 100
$$

\section{Results and Discussion}

Biological control using nematophagous fungi has the potential to become an important strategy to control gastrointestinal helminths in domestic animals. Larsen e Nansen [13], have shown that the fungus Pleurotus spp has nematicidal activity and can therefore be considered a nematophagous fungus. Although there are studies that demonstrate the action of the fungus Pleurotus spp as a predator of nematodes larvae, there are no studies demonstrating its action on larvae of the Ancylostoma spp genre.

Here, the predatory activity of the fungus P. eryngii on $A$. caninum larvae was demonstrated, verifying that the fungal isolate was able to interact and prey on the larvae during the experiment. The average number of L3 recovered from the control group was significantly higher than the average from the treated group. The $P$. eryngii fungal isolate reduced the average number of $A$. caninum L3 compared to control $(p<0.01)$ and presented a reduction percentage of $47.56 \%$.The average number of L3 recovered in the treated group was 32.2 ( \pm 15.3 ) while the average in the control group was $72.88( \pm 27.0)$.

Thorn and Barron [8] were the first to report that wood decomposing fungi have the ability to capture, kill and digest nematodes. They showed that 11 species of fungi belonging to the order Agaricales, including Pleurotus ostreatus, have the ability to kill root-knot nematodes. Palizi et al. [14] reported that this species reduced the formation of cysts from the nematode Heterodera schachtii and Marino and Silva [15], deduced that the use of Pleurotus ostreatus reduces the number of root-knot nematodes and egg mass of Meloidogyne incognita.

Kwok et al. [10] cited that P. ostreatus and related species have specialized cells in hyphae capable of producing droplets of a substance containing toxins. The nematode when in contact with this substance suffers paralysis and lysis of the cuticle. Although alive, the nematode remains immobile and liquids outside theirtissues stimulate the growth of the fungus hyphae in its direction, in a process of chemotaxis. These hyphae penetrate, and when in the nematodes tissues digest them and absorb the released nutrients. Satou et al. [16] observed that $P$. ostreatus produce bubbles with anti-nematode activity. These bubbles promoted reduction of the nematodes "head" due to the release of linoleic acid in the solution. In the present study it was observed that the L3 of A. caninum suffered action of the fungal isolate $P$. eryngii, since it was possible to visualize the presence of hyphae and small droplets/bubbles inside and at the periphery of the larvae and due to the increased number of such droplets within the larvae over the 7 days (Figure 1). In trial conducted 

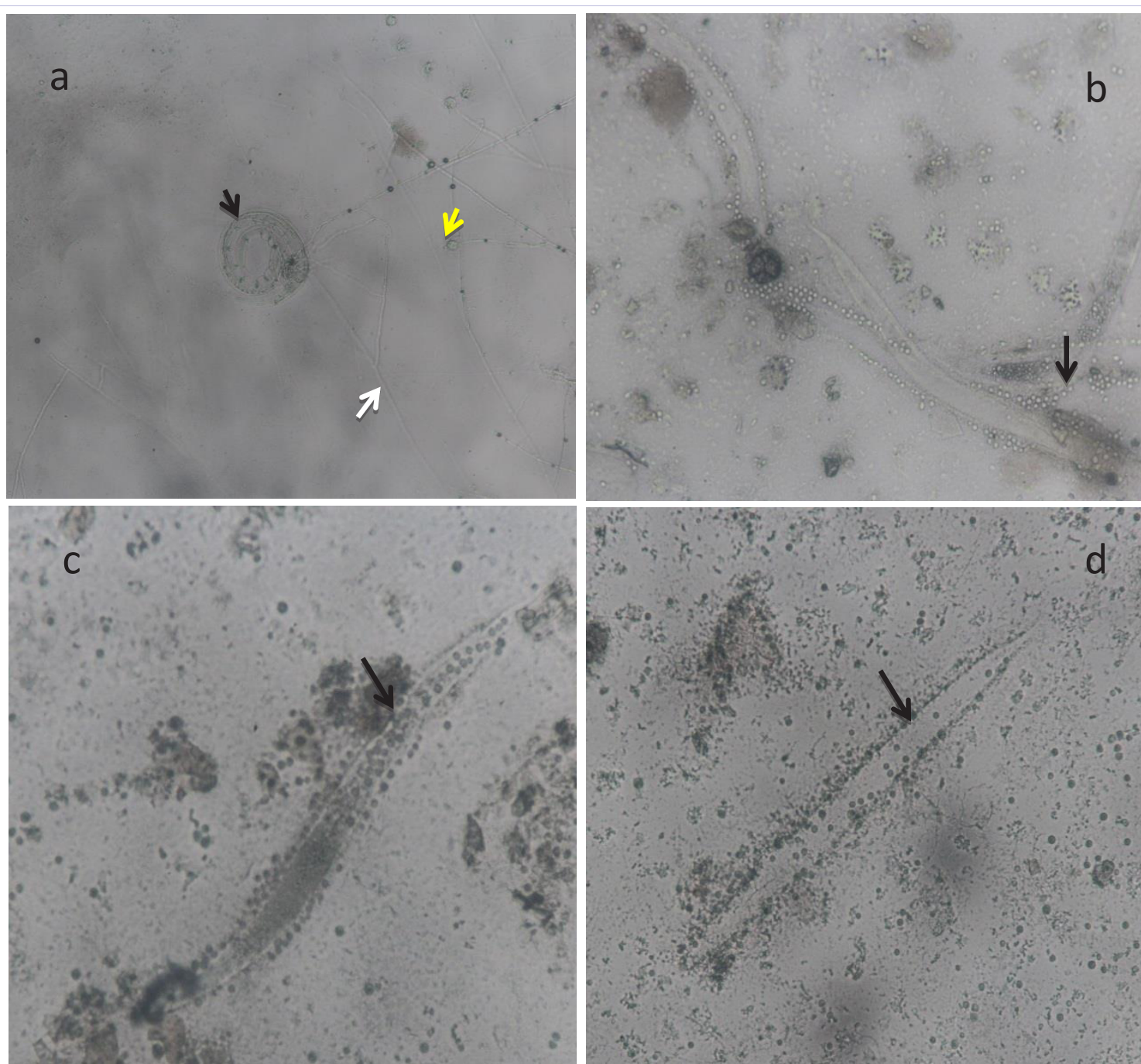

Figure 1: A) Larvae of Ancylostoma caninum (black arrow), hyphae of Pleurotus eryngii (white arrow) and droplet produced by the fungus (yellow arrow). B) Larvae of Ancylostoma caninum with droplets produced by the fungus Pleurotus eryngii in contact with the surface of the larvae (black arrow). C) Larvae of Ancylostoma caninum with droplets produced by Pleurotus eryngii inside the larvae (black arrow).D) Larvae of Ancylostoma caninum digested by the fungus Pleurotus eryngii. Light microscopy - 10x objective.

by Satou et al. [16] in which fungal isolates of P. ostreatus were used on free-living nematodes (Diplogastridae) spherical buttons were also observedby scanning electron microscopy and optical microscopy.

In the study involving the predatory activities of Ancylostoma spp L3, the works of Maciel et al. [17] demonstrated that nematophagous fungi from the Arthrobotrys, Duddingtonia and Monacrosporium genera presented in vitro predatory activity and at the end of the experiment observed percentage values of $88.76 \%, 97.75 \%$ and $89.89 \%$, respectively. However, as mentioned earlier, this is the first report of P. eryngii activity on Ancylostoma L3 and comparatively it can be noted that, the studied fungus can be used in future experiments involving predation of potentially zoonotic helminth larvae, opening a new possibility of in vitro and in vivo studies.

The average of the larvae in the control and treated groups for 7 consecutive days of the experiment are shown in Table 1. Significant values were found $(p<0.01)$ between the averages of the treated and control group, in which there was a consecutive decrease from day 1 to day 7 of the number of larvae in both treated and control groups. Significant difference $(p<0.01)$ was also found between the days in the treated group compared to day 1 of treatment. These data corroborate with data found by other authors who also used fungal isolates of Pleurotus spp, but larvae of other nematodes.

Satou et al. [16] in microscopic examination of the inoculated fungus (Pleurotus pulmonarius) revealed the presence of secretory cells with tiny droplets of fluid across the agar surface and it became obvious that the larvae of parasites were immobilized by contact with the fungus within one to two hours, and no later than four hours of exposure there was a dramatic reduction in the number of mobile larvae of all species (Ostertagia ostertagi, 
Table 1: Efficiency of Pleurotus eryngii fungal isolate in reducing the number of Ancylostoma caninum L3 larvae for 7 consecutive days.

\begin{tabular}{|l|l|l|}
\hline \multicolumn{2}{|c|}{ Average of the larvae ( \pm SD) } \\
\hline Day 1 & Treated & Control \\
\hline Day 2 & $7.6( \pm 3.1)^{*}$ & $13.5( \pm 5.1)$ \\
\hline Day 3 & $6.6( \pm 2.8)^{*}$ & $8.4( \pm 4.8)$ \\
\hline Day 4 & $6.4( \pm 2.9)^{* \#}$ & $5.0( \pm 2.7)$ \\
\hline Day 5 & $6.1( \pm 2.1)^{* \#}$ & $2.9( \pm 2.8)$ \\
\hline Day 6 & $4.9( \pm 2.3)^{* \#}$ & $1.8( \pm 2.8)$ \\
\hline Day 7 & $4.9( \pm 2.4)^{* \#}$ & $1.8( \pm 2.9)$ \\
\hline * Comparison between columns: Average from the treated and control groups of the respective day differ from each other $(p<0.01) . *$ Comparison \\
between lines: the average from the treated group differs $(p<0.01)$ from the average from the treated group on day 1.
\end{tabular}

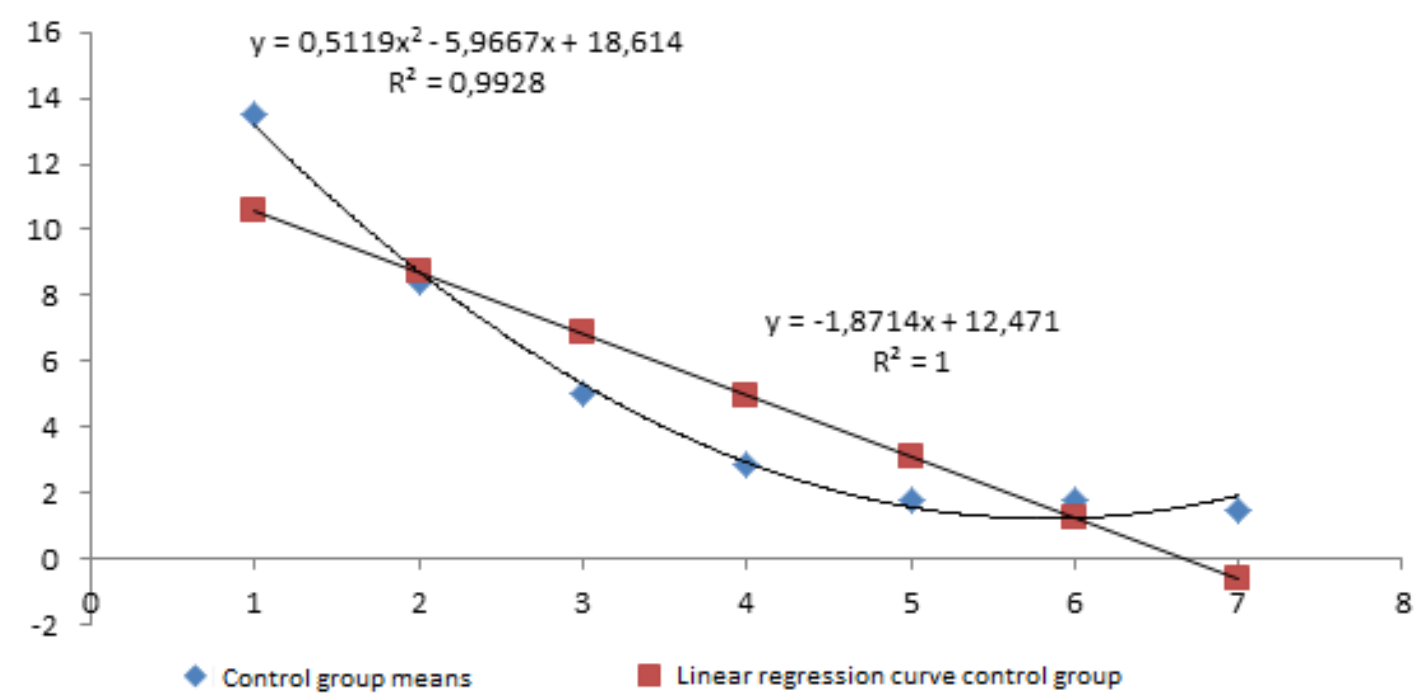

Figure 2: Linear regression curve calculated through the average of the Ancylostoma caninum larvae from the control group in function of time (days 1 to 7$)$.

Cooperia oncophora, Oesophagostomum quadrispinulatum and Cyathostomum) and after eight hours, no more larvae motility was recorded.

In an experiment conducted by Graminha et al. [18] the pathogenicity of the fungus Arthrobotrys musiformis and $A$. conoides on infective larvae of Haemonchus contortus and Ancylostoma spp and embryonated eggs of Ascaridiagalli was evaluated and it was found that predation of both nematodes by $A$. conoides was crescent, obtaining the maximum predation on Ancylostoma spp. on the fourth day, whereas maximum $H$. contortus predation was only obtained on the sixth day and although the efficiency of both fungi was higher for $H$. contortus larvae than the ones from Ancylostoma spp., it was observed that predation tendency for both nematodes was crescent during the trial period.

The data presented in the present study showed that the number of L3 found in the control group decreased gradually throughout the experiment (Table 1). This can be explained by migration of L3 to the periphery of the petri dishes, since they migrate in search of a place in the medium with more nutrition and moisture. In a study by Larsen and Nansen [13], L3 of different nematodes (Ostertagia ostertagi, Cooperia oncophora, Oesophagostomum quadrispinulatum and Cyathostomum species) tended to distort the mycelium of the fungus P. pulmonarius by vigorous movement and after three or four hours the larvae were gathered around the periphery of the petri dishes where they were difficult to identify and count as movable or immovable, with data being recorded along the first three or four hours of exposure. This larval migration to the periphery of the plate where there is more moisture was also observed by Carvalho et al. [6] e Braga e Araujo [19].

Based on the values found in Table 1, the adjusted regression equations for the treated and control groups were estimated. The negative coefficients of linear regression indicates a descendent 


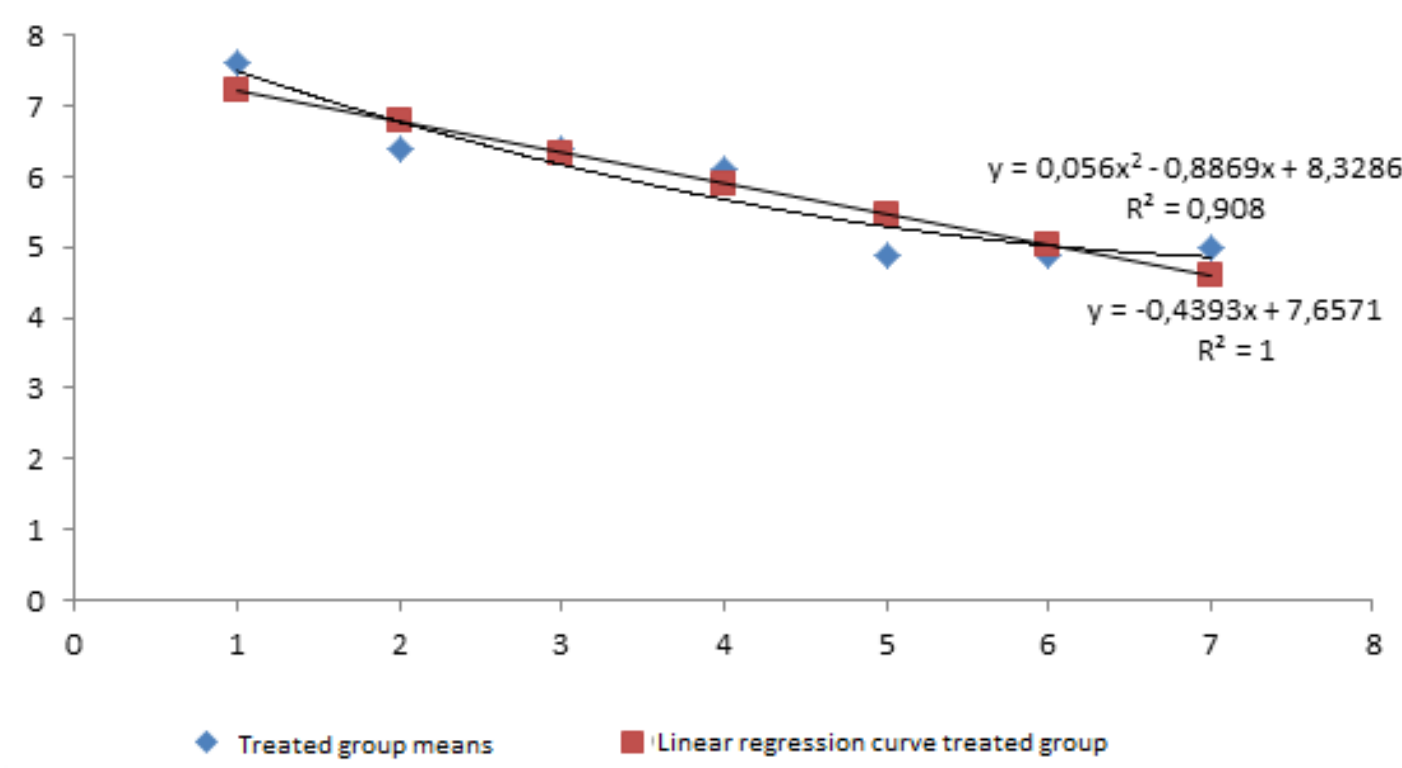

Figure 3: Linear regression curve calculated through the average of the Ancylostomsa caninum larvae from the treated group in function of time (days 1 to 7$)$.

behavior of the regression curves, showing that the days directly influenced on predation of $A$. caninum L3, ie for each day added to the experiment, the average of the larvae decreased from 1.87 in the control (Figure 2) and 0.43 for treated group (Figure 3). The reduction of L3 in the control group during the study however was caused by the migration of the larvae to the periphery of the Petri dishes, place where the moisture level was higher.

Compared with other trials conducted with the same nematode (Ancylostoma spp), but with other nematophagous isolates (Monacrosporiumthaumasium, Arthrobotrysrobustaand Duddingtonia flagrans) the linear reduction coefficient was 0.23 ; 0.24 and 0.28 respectively in the different treated groups [17]. However, in a study by Braga et al. [20] predation efficiency of Duddingtonia flagrans, Monacrosporium thaumasium, M. sinense and Arthrobotrys robusta fungi on Ancylostoma ceylanicum L3 was established and the authors reported linear coefficient values in the treated groups of $0.73 ; 0.76 ; 0.78$ and 0.82 respectively. Comparing the linear coefficient values of reduction found in this study with those recorded in the assays performed by Maciel et al. [17] it was observed that the fungus P. eryngii showed higher linear coefficient value (0.43), suggesting that for each day added to the experiment the average of L3 decreased, demonstrating a greater time influence on $A$. caninum larvae predationfrom the current study. However, when comparing the linear coefficient of reduction of the present study with Braga et al. [20] the linear coefficient reduction values were higher for all fungal species studied.

The results obtained in this study confirm previous reports of nematophagous fungi efficiency in the control of potentially zoonotic nematode larvae. It is estimated that about 1 billion people are currently infected with geohelminths, mainly due to contact with the soil, indicating that this is an important route of human infection, which is associated with serious health consequences if untreated [19]. Furthermore, studies on parasites that infect domestic animals have caused great interest due to the close relationship between man and animals, which may be a public health problem. Among the helminths with zoonotic potential, one can highlight those of the Ancylostoma genre [5].

Therefore, it is necessary to know the role of all organisms involved in the biocontrol of nematodes [19]. According to Araújo et al. [5] it is essential that funding agencies support research in this area because many basic aspects of biology, epidemiology and host-pathogen interaction need to be studied. To the industry it would fit the very important role of developing commercially viable formulations. Helminths are the conduits of soil-transmitted infections and a major health problem. In this study, the nematicidal activity of Pleurotus eryngii on the Ancylostoma caninum L3 was confirmed by the reduction in the number of larvae after treatment with the fungus.

\section{Acknowledgments}

The authors also would like to thank CNPq, Capes, Fapes and Fapemig for financial support and grant concession.

\section{References}

1. Robertson ID, Irwin PJ, Lymbery AJ, Thompson RC. The role of companion animals in the emergence of parasitic zoonoses. Int J Parasitol. 2000;30(12-13):1369-1377.

2. Braga FR, Araujo JM, Silva AR, Araújo JV, Carvalho RO, Soares FE, et al. [Ovicidal action of a crude enzymatic extract of fungus Pochonia chlamydosporia against Ancylostoma sp eggs]. Rev Soc Bras Med Trop. 2011;44(1):116-118.

3. Carvalho RO, Araujo JV, Braga FR, Ferreira SR, Araujo JM, Silva AR, et al. Biological control of Ancylostomosis in dogs using the nematode- 
trapping fungus Monacrosporium thaumasium in southeastern Brazil. Vet Parasitol. 2009;165(1-2):179-83. doi: 10.1016/j. vetpar.2009.06.024.

4. Araujo JV, Freita BW, Vieira TC, Campos AK. [Evaluation of nematode predacious fungus Duddingtonia flagrans on infective Haemonchus contortus and Strongyloides papillosus larvae of goats]. Rev Bras Parasitol Vet. 2006;15(2):76-9.

5. Araujo JM, Araujo JV, Braga FR, Ferreira SR, Tavela AO. Predatory activity of chlamydospores of the fungus Pochonia chlamydosporia on Toxocara canis eggs under laboratory conditions. Rev Bras Parasito Vet. 2013;22(1):171-4.

6. Carvalho RO, Araujo JV, Braga FR, Araujo JM, Silva AR, Tavela AO. Predatory activity of nematophagous fungi on infective larvae of Ancylostoma sp.: evaluation in vitro and after passing through the gastrointestinal tract of dogs. J Helminthol. 2009; 83(3): 231-6. doi: $10.1017 /$ S0022149X08158965.

7. Dias AS, Araujo JV, Braga FR, Araujo JM, Puppin AC, Fernandes FM, et al. Biological control of Fasciola hepatica eggs with the Pochonia chlamydosporia fungus after passing through the cattle gastrointestinal tract. Parasitol Res. 2012;110(2):663-7. doi: 10.1007/ s00436-011-2538-6.

8. Thorn RG, Barron GL. Carnivorous mushrooms. Science. 1984;224(4644):76-78.

9. Yang J, Liang L, Li J, Zhang KQ. Nematicidal enzymes from microorganisms and their applications. Appl Microbiol Biotechnol 2013;97(16):7081-7-95. doi: 10.1007/s00253-013-5045-0.

10. Kwok OC, Plattner R, Weisleder D, Wicklow DT. A nematicidal toxin from Pleurotus ostreatus NRRL 3526. J Chem Ecol. 1992;18(2):12736. doi: 10.1007/BF00993748.

11. Araujo JV, Santos MA, Ferraz S, Maia AS. Antagonistic effect of predacious Arthrobotrys fungi on infective Haemonchus placei larvae. J Helminthol. 1993;67(2):136-138.

12. Braga FR, Silva AR, Araujo JM, Carvalho RO, Araujo JV, Frassy
LN. Predatory activity of the nematophagous fungi Duddingtonia flagrans, Monacrosporium thaumasium and Arthrobotrys robusta on Strongyloides stercoralis infective larvae. Rev Soc Bras Med Trop. 2010;43(5):588-590.

13. Larsen M, Nansen P. Ability of the fungus Pleurotus pulmonarius to immobilise preparasitic nematode larvae. Res Vet Sci. 1991;51(3):246249.

14. Palizi P, Goltapeh EM, Pourjam E, Safaie N. Potential of oyster mushrooms fot the biocontrol of sugar beet nematode (Heterodera schachtii). J Plant Protect Res. 2009;49(1):27-34.

15. Marino RH, Silva DGC. Controle de nematoide de galhas por Pleurotus ostreatus. Scientia Plena. 2013;9(10):100-202.

16. Satou T, Kaneko K, Li W, Koike K. The toxin produced by pleurotus ostreatus reduces the head size of nematodes. Biol Pharm Bull. 2008; 31(4):574-576

17. Maciel AS, Araujo JV, Cecon PR. In vitro predatory activity of fungi Arthrobotrys robusta, Duddingtonia flagrans and Monacrosporium thaumasium on infective larvae of Ancylostoma spp. of dogs. Rev Bras Parasitol Vet. 2006;15(2):71-5.

18. Graminha EBN, Maia AS, Santos JM, Cândido RC, Silva GS, Costa AJ. Avaliação in vitro da patogenicidade de fungos predadores de nematoides parasitos de animais domésticos. Semina. 2001;22(1):1116.

19. Braga FR, Araujo JV. Nematophagous fungi for biological control of gastrointestinal nematodes in domestic animals. Appl Microbiol Biotechnol. 2014;98(1):71-82. doi: 10.1007/s00253-013-5366-z.

20. Braga FR, Silva AR, Carvalho RO, Araújo JV, Guimarães PH, Fujiwara RT, et al. In vitro predatory activity of the fungi Duddingtonia flagrans, Monacrosporium thaumasium, Monacrosporium sinense and Arthrobotrys robusta on Ancylostoma ceylanicum thirdstage larvae. Vet Microbiol. 2010;146(1-2):183-6. doi: 10.1016/j. vetmic.2010.05.003. 